\title{
A 21st century approach to the condition surveying of building services systems
}

Received (in revised form): 11th July, 2006

\author{
Hsieh-Min Loy DipBSE, BEng(Hons), AMIMECHE
}

is a project manager/cost analyst in the Facilities Group of Faber Maunsell Ltd. He has extensive research experience into life-cycle and failure probability studies from Reading University.

\section{Pat Coleman BEng(Hons), CEng, MCIBSE, CFM}

is the Director of Facilities Engineering at Faber Maunsell Ltd. For the last 14 years Pat has been providing operational engineering design, technical advice and installation management focused on achieving the best performance results from buildings in the managed property market.

\begin{abstract}
Condition surveys of building services systems provide owners/occupiers with 'face value' information on the relative state of their building's assets. Information obtained from condition surveys is based solely on the life-cycle prediction of each asset. The advisory reports produced from condition surveys will not consider the relative consequence of plant failure on the occupier's business operations. It is this information which is essential for a building's management to prioritise a mitigation programme of remedial works, planned in terms of business needs and user requirements. Furthermore, it is this risk versus consequence information which is the essential driver for effective expenditure management.

A correlation exists between the performance of the building and the performance of the business operated from within it. Risks, as related to the functional operation of buildings, generally fall into three interrelated categories: business, environmental and health and safety. This paper describes a methodical, informed and judgmental approach by which building services systems can be appraised, in order to provide budgetary advice specific to the occupier's risk and consequence scenarios.
\end{abstract}

\section{Keywords:}

condition survey, risks, building services, CSR, OFR

Faber Maunsell Ltd Marlborough House Upper Marlborough Road St Albans, Hertfordshire AL1 3UT, UK

Tel: +44 (o) 2087845784 Fax: + 44 (o) 2087845630 E-mail: pat.coleman@ fabermaunsell.com

\section{INTRODUCTION}

Buildings exist for a wide range of purposes, which are specific and often particular to the occupied use of the premises. Whatever the operational purpose may be, it usually involves a network of relationships including people, places, processes, systems, funds, form and function. A change in any of the user's characteristics may impact significantly upon the other relationships and bring about the need to change the performance criteria of the building services. Throughout the life cycle of 
a building, from concept through to disposal, user characteristics are likely to change and, when they do, the occupier may need to consider a corresponding change in design parameters, control sequences and decision management of the revenue budget. This has even greater significance when an occupied building is designed to support a flow of definitive activities for which the user characteristics may no longer be applicable and where a change of use has evolved, without being consciously recognised.

Building services systems should be 'tuned' at the point of occupancy to meet with the defined activity requirements of the occupier, to achieve the best operational performance from the installed facilities and avoid discontenting the business, user staff and clientele (Loy and Coleman, 2006). To achieve the best performance from a building, professionals involved in managing properties need to begin to implement more customer-focused practices to provide owners/stakeholders with advice which is directly related to the occupancy of the building (Wood, 2003; Thurm, 2005). A number of customer-focused practices exist in order to align asset value to the needs of the occupier. A full analysis of the operational profile of a building could be captured by a combination of the following.

- A due diligence appraisal of the design, to confirm fitness for purpose.

- Validation measurement of actual performance, to establish sufficiency.

- A post-occupancy evaluation (POE) (Clements-Croome, 2000; Jaunzens et al., 2003; Bordass and Leaman, 2005) to understand the dynamics of the buildings and how the place and space are utilised in relation to the occupants and their activities.

- A business continuity/resilience appraisal, to define points of likely interruption to normal operation.

- A condition survey, to ascertain the current state of the building and its assets.

- An intrusive survey, to understand elements, normally hidden, which could impact upon the performance of the building or its components.

This paper illustrates a methodological approach for delivering a tailormade, risk-based, condition survey, to capture the particular consequential effects on the user as a result of a failure of each building services asset. Risk is the key attribute for establishing pertinent advice as to whether an asset requires no attention, repair or planned replacement. Risk is the defining factor when estimating the importance of each asset to the operation of the property.

\section{RISK}

Risk, as defined in BS 8444 (British Standards Institution (BSI), 1996), is:

\footnotetext{
'the combination of the frequency, or probability, of occurrence and the consequences of a specified hazardous event. Note: the concept of risk always has two elements: the frequency (or probability) with which a hazardous event occurs and the consequences of the hazardous event.'
} 
Moreover, it is said that the construction industry is subjected to more risk and uncertainty than many other industries (Norman and Flanagan, 1993). With the built environment involving so many parties and stakeholders, it is clear that risk needs consideration and management.

One of the fundamentals of risk management is that all individuals and the decisions they make do matter and do make a difference (Smith, 2003). Thus, the concept of risk can be applied to almost all decisionmaking actions of which the consequences are uncertain. This uncertainty arises because professionals provide advice on the basis of future predictions, which by their very nature are uncertain. Once a risk has been identified and defined, however, it ceases to be a risk and becomes a management issue, which should be addressed accordingly.

\section{CONDITION SURVEY}

A condition survey is defined as:

'the collection of data about the condition of a building, estate or portfolio; assessing how that condition compares to a pre-determined standard, to identify any actions necessary to achieve that standard now; and maintain it there over a specified time horizon; the purpose being to support management decision making' (RICS, 1997).

Condition surveys are required throughout the life cycle of any property as a method of providing the building's management with cost planning advice about undertaking plant replacement works. Such advice is critical as it forms the basic data for effectively managing the maintenance revenue budget, while minimising any disruptive impact on occupiers' quiet and comfortable continuance of their operations.

Condition surveys also present an excellent opportunity to review any shift changes within the business, in terms of the user characteristics (ie people, places, processes, systems, funds, form and function). State-ofrepair appraisal surveys should be undertaken periodically in order to help organisations achieve the needs of their business, its user groups and associated stakeholders. If the survey report was drafted particular to each occupier it could become a beneficial decision-making tool, to plan the introduction of required changes and, in so doing, stop the continuance of any negative routines (Ackoff, 1999). The best management doctrine is to undertake a building condition survey on a five-yearly basis, supplemented by a two-yearly superficial inspection (BSI, 1986).

During the traditional survey process, in the commercial sector, the consultant considers the condition rating of each asset by using either the NHS asset grading condition (AGC) rating system as shown in Table 1 or using other similar systems (Nanayakkara, 2000; RICS, 1997). In addition, a number of condition surveys are engaged on the basis of using consequence grading criteria (CGC) as shown in Table 2, which help to define the likelihood of the event happening as a result of the asset failing to perform its intended function. In applying CGC, however, building professionals should be aware that the business needs, environmental and health and safety requirements will vary for different organisations and their stakeholders. Because of different occupier attributes, every 
Table I: Asset grading condition (AGC) (NHS, 1993)

\begin{tabular}{ll}
\hline Grading & Description of grading \\
\hline A & $\begin{array}{l}\text { The element is as new and can be expected to } \\
\text { perform adequately to its full normal life } \\
\text { The element is sound, operationally safe and } \\
\text { exhibits only minor deterioration } \\
\text { The element is operational but major repair or } \\
\text { replacement will be needed soon, that is } \\
\text { within three years for a building and one year } \\
\text { for an engineering element }\end{array}$ \\
The element runs a serious risk of imminent \\
breakdown \\
A rating added to C or D to indicate that it is \\
impossible to improve without replacement
\end{tabular}

Table 2: Consequence grading criteria (CGC)

\begin{tabular}{ll}
\hline Grading & Description of grading \\
\hline $\mathbf{I}$ & $\begin{array}{l}\text { No disruption to the business, no harm to human } \\
\text { and/or no harm to the environment } \\
\text { Minimal disruption to the business, minor hazards exist } \\
\text { which could cause injury to humans and/or minimal } \\
\text { damage to the environment } \\
\text { Moderate disruption to the business, injuries to humans } \\
\text { are easily recoverable and/or damage to the } \\
\text { environment would be easily reversible }\end{array}$ \\
$\mathbf{4}$ & $\begin{array}{l}\text { Temporary business disruption, disability to human } \\
\text { and/or recoverable damage to the environment } \\
\text { Permanent business disruption, disabilities or fatalities } \\
\text { and detrimental impact to the environment }\end{array}$ \\
\hline
\end{tabular}

condition survey report would be more tangible if it reflected the particular occupancy needs of the instructing organisation.

\section{HOW CAN CONDITION SURVEYS BE TAILOR-MADE TO MEET THE NEEDS OF EACH CLIENT?}

Building services consultants could add more value by first identifying the client's business and stakeholder drivers and the operational needs of their building. Using such a mindset avoids the client creating their own interpretations and ensures that the condition report presents directive information by focusing on 'real' outcomes, ie those incidents which will affect the user/occupier. Real outcomes will have varying degrees of risk and value to business functions, the needs of the business and stakeholders as identified by Ackoff (1999).

In the same organisation, different departmental stakeholders require different needs to be fulfilled by the building, therefore the perceived risks and values of the building services systems can be different. This is where a 'traditional' condition survey, using condition and grading criteria, may not match the 'real' value of each building services asset to the user's business function.

In the ever-increasing pace of business and society, there is a continual need to deliver maximum output and performance at minimum cost. There 
is then a point at which trade-offs are made in order to achieve an effective balance of performance versus cost. Inevitably, the constant pressure on organisations to deliver their mission statement can result in management teams spending inadequate time on creating an appropriate operational strategy that will meet the immediate needs of the business and its longterm future plans.

The ethos of the managed property industry (CIBSE, 1986) has been to use a strategy of replacing assets at the time of minimum total impact (also known as lowest whole life cost), where the preventative costs (operation and maintenance costs) intersect with the risk exposures (the performance and value of the asset to an organisation), as shown in Figure 1. Although this strategy attempts to optimise the return on investment of the asset, in reality it fails to take into account the operational needs and the risks the organisation is exposed to, due to the operating conditions of some of the assets. The European 'MACRO' Project (Euraka Project EU 1488) was backed by the DTI and took five years to complete, where companies got together and researched into methods for resolving cost/risk/performance conflicts in the management of their physical assets. The objective of the research was to 'Research, collate and develop best practice in Asset Management decision-making, particularly where hard data was not available or adequate' (Skillsware, 2006). The deliverables were seven suites of decision-support methods, training modules and software tools that were more advanced than any other methods for identifying and quantifying the cost/risk optimal solutions.

Previous research has shown that the intersection point of preventative costs and risk exposure is where the replacement costs equal the perceived risks. The optimum replacement strategy, in practice, can vary from the anticipated ideal optimum point, where the two conflicting component points meet, as shown in Figure 1 (Woodhouse, 2001). The implementation of the above methodology was undertaken by

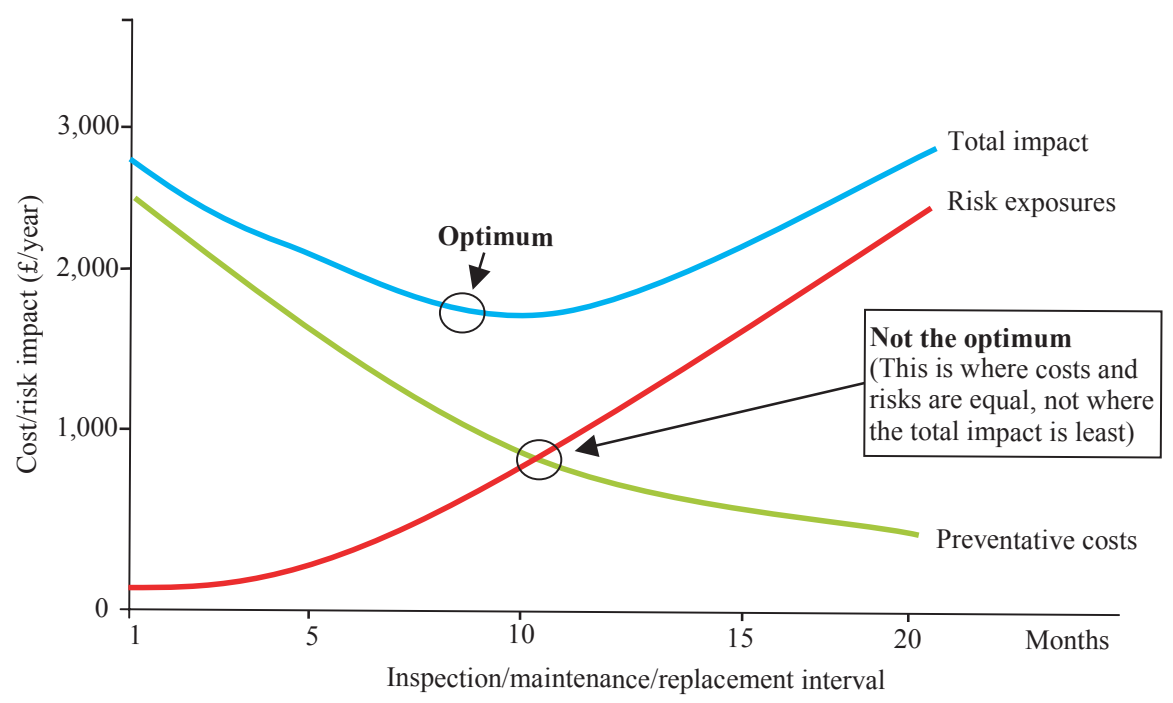

Figure 1: Optimum is defined as minimal total business impact (adapted from Woodhouse, 200I) 
Severn Trent Water and the combined impact of Reliability Centred Maintenance/MACRO procedures saved the company over 30 per cent of its total maintenance costs (Woodhouse, 2003).

Using risk as a driver for optimising the performance of an asset will enable building services consultants who carry out the condition surveys to prioritise their findings in the form of a risk assessment, to improve the quality of the resulting reports particular to the occupier's operational needs. The use of a high-medium-low risk matrix can assess the consequences to a business effectively, and highlight the likelihood of failure of a building services asset.

\section{IMPLEMENTING A HIGH-MEDIUM-LOW RISK MATRIX APPROACH TO CONDITION REPORTING}

Decision making can quickly come to a halt if the various stakeholders disagree on the assumptions that will form the basis of the analysis, therefore it is essential to agree key operational drivers before commencing the survey. In order to report effectively, it is necessary to prioritise the condition of the asset relative to the consequence of failure to meet its intended function. The use of a high-medium-low risk matrix will allow stakeholders to focus quickly on the key issues to be tackled.

In order to achieve the objectives of an organisation, the quality of the communication process is vital for delivering both business needs and stakeholder value. It is essential that common terminology is used, as highlighted by the National Research Council (US) Committee on Business Strategies for Public Capital Investment (2004), or misunderstanding easily can be developed if consultants, contractors, accountants, senior executives and facilities managers use their own particular terminology and style of interaction. Lack of clarity can lead easily to miscommunications resulting in loss of potential benefits and opportunities for investing in a building, where time delays commonly can result in huge financial implications.

Some existing forms of condition survey consider risk issues purely by means of the consultant's 'gut-feel' as a result of their instinct and experience. A systematic approach will make the appraising process more explicit, by properly describing the key drivers of the building, and should form the basis of the management strategy supported by competent judgmental decisions.

The impact of risk (Godfrey, 1996) can be measured as the likelihood of a specific unwanted event multiplied by its unwanted consequence or loss:

Impact of risk $=$ Likelihood $\times$ Consequence

If the likelihood and consequence of the ability of an asset to perform its intended function are unacceptable, then the risk must be managed or mitigated. In this paper, the impact of risk relates to and is measured as the condition of the asset, as a specific unfavourable criterion and its consequence or loss:

Impact of risk $=$ Condition of asset $\times$ Consequence 
Table 3: Risk/scoring matrix

\begin{tabular}{|c|c|c|c|c|c|c|}
\hline \multirow{7}{*}{ 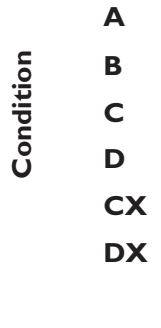 } & Zero & Low & Low & Low & Low & Low \\
\hline & Zero & Low & Low & Medium & Medium & Medium \\
\hline & Zero & Medium & Medium & Medium & High & High \\
\hline & Zero & Medium & High & High & High & High \\
\hline & Zero & Medium & High & High & High & High \\
\hline & Zero & Medium & High & High & High & High \\
\hline & & I & 2 & 3 & 4 & 5 \\
\hline
\end{tabular}

Where:

High: Seriously affects the business and stakeholders' needs and is a breach of statutory requirements.

Medium: Possibility of business disruption and affecting stakeholders' needs if not managed effectively, which may result in a breach of statutory requirements.

Low: Business as usual, stakeholders' needs intact and remote risks of breaching statutory requirements.

Zero: No effect on the business, stakeholders' needs intact and no risks of breaching statutory requirements.

Therefore, incorporating a risk assessment matrix as a criticality rating mechanism is a method of prioritising the decision-making process. The result is a risk assessment matrix (RAM) developed as shown in Table 3, which schedules the stakeholders' needs in terms of business, environmental and health and safety requirements. Moreover, and more recently, there is now a requirement to consider social impacts. As such, building services consultants should prepare themselves to address corporate social responsibility (CSR) issues and the incoming Operating and Financial Review (OFR) Regulation (DTI, 2004a) (where companies will report on the intangible aspect of their organisation, which could include workplace management and the welfare of their employees). Since 1999 the UK Government has been engaged in creating the sustainable development strategy 'a better quality life', of which one of the outcomes is to disseminate the way its policies and practices contribute towards sustainable development. It is through this movement that the Government would like to engage private-sector organisations to contribute towards sustainable goals (DTI, 2004b). This could mean more proactive business management of the risks and opportunities that the economic, environmental and social performance presents. Ultimately, no matter how the OFR impacts on the CSR of a business, the concept of sustainability will encourage businesses to give closer attention to the whole impact of their commercial activities for their stakeholders. In addition, businesses now face informed and active pressures from a range of new stakeholder groups, which were not very visible in the past (Robins, 2006).

Unfortunately, the built environment which sustains people's lives and protects and enhances the wellbeing of stakeholders also consumes energy, produces waste and requires the attention of human resources. It is the combination of these impacts that may influence how stakeholders' needs should be addressed. 


\section{An example}

Consider a property which has four central chillers (the plant item which produces chilled water at $6^{\circ} \mathrm{C}$ to cool the outside air supplied to the property) which serve five zones of air-conditioning distribution, with different operational functions, where each zone is installed with a variable number of terminal cooling units. The whole system is being assessed as part of the condition survey.

- Zone One provides the cooling needs of the IT server equipment for the entire facility and, for reasons of resilience, is duplicated by a refrigerant gas-based system, thus, in the event of a failure of the chilled water system, conditions can be sustained by a secondary direct expansion (DX) gas type of cooling system.

- Zone Two provides cooling to the central offices.

- Zone Three provides cooling for the warehouse.

- Zone Four provides cooling for the reception area.

- Zone Five provides cooling for the print room.

The condition report (Table 4) defines a condition ' $\mathrm{C}$ ' rating for all chilled water cooling circuits and condition ' $\mathrm{D}$ ' for the refrigerant gas type of cooling system. The two air cooling systems serving the IT equipment room are recorded as being at a high risk of the likelihood of one or both of the systems failing to perform their intended functions, which is unacceptable for the operation of the facility. A failure of the cooling units serving the central offices would represent a medium risk, because of the scale of the ensuing effect on productivity and staff retention. A failure of the cooling circuit serving the warehouse would have zero effect on the business, as for the past two years the company has only stored stone and cement products, which do not require environmental control conditions. Lack of cooling to the reception area would represent a moderate consequence to the business, as any discomfort caused could be considered minimal because of the infrequent number of client visitors to the building and thus it represents a low risk to the business. Because the photocopying processors in the print room are newly installed and highly energy efficient, the consequence of failure of the cooling unit there is considered to be insignificant and as such represents a zero risk to the business. The terminal cooling units in the warehouse and print room, therefore, could be turned off to save electricity and only used as spare parts to repair the units serving the IT room, offices and reception area.

Table 4: Summary of asset condition

\begin{tabular}{lllll}
\hline Asset location & Asset & Condition & Consequence & Risk \\
\hline IT server room & 20 fan coil units & C & 5 & High \\
IT server room & 20 DX units & D & 5 & High \\
Offices & 10 fan coil units & C & 3 & Medium \\
Warehouse & 20 fan coil units & C & 1 & Low \\
Reception area & 4 fan coil units & C & 2 & Zero \\
Print room & 4 fan coil units & C & I & \\
\hline
\end{tabular}


Therefore, prioritising work by using a risk matrix allows the facilities teams to schedule work according to the needs of the business, to improve efficiency, productivity, resilience, the environment and the functional value of the assets and proves economically beneficial for management purposes.

\section{CONCLUSION}

Without making considerations about risk, the advice could have been given for the replacement of all four chillers (at say $£ 75,000$ each), terminal cooling units (at say $£ 1,000$ each) and the DX cooling system (at say $£ 50,000$ ). But because risk prioritisation was defined and associated against each asset, each stakeholder will be able to associate the findings and recommendations against their own needs. Furthermore, if the surveyor was aware of the business risk, their advice could be:

- Replace the DX system, in the immediate term.

- Replace the four chillers with perhaps only two chillers of the same size, in the short term. This reduction in the central plant would be appropriate to match the reduced volume of chilled water required by the building, because of the disconnection of the warehouse and print room circuits from the central system. This reduced cooling provision would also allow reduction of the pumping capacity and controls system, all saving both capital and revenue costs for the business.

- Replace the cooling system to the offices after replacement of the cooling system to the IT equipment room.

- As the final sequence of works, consider whether it would be appropriate to install a small standalone cooling system to serve the reception area, at low capital and running costs.

Such advice, which includes risk considerations, will provide a systematic approach to dealing with and making the building fit for its purpose, without detriment to the building/organisation. This continuous improvement process is aimed at benefiting the occupier's business results, increasing property value and minimising losses and user dissatisfaction, by ensuring the building services systems operate more specifically to the occupier's requirements. Hence, this methodical, informed and judgmental approach will lead to a cost-effective solution that will underpin the 'real' value of the building.

\section{References}

Ackoff, R. (1999) Ackoff's Best: His Classic Writings on Management, John Wiley \& Sons, New York, NY.

Bordass, W. and Leaman, A. (2005) 'Making feedback and post-occupancy routine 1: A portfolio of feedback techniques', Building Research \& Information, 33(4), 347-352.

British Standards Institution (BSI) (1986) BS 8210:1986. Guide to Building Maintenance Management, BSI, London, UK.

British Standards Institution (BSI) (1996) BS 8444:1996. Risk Management — Guide to Risk Analysis of Technological Systems, BSI, London, UK.

Chartered Institution of Building Services Engineers (CIBSE) (1986) CIBSE Guide: Volume B Instalation and Equipment Data, CIBSE, London, UK. 
Clements-Croome, D. (ed.) (2000) Creating the Productive Workplace, E \& FN Spon, London, UK.

Department of Trade and Industry (DTI) (2004a) Draft Regulations on the Operating and Financial Review and Directors' Report - A Consultative Document, HMSO, available from: www.cbi. org.uk/ndbs/positiondoc.nsf/1f08ec61711f29768025672a0055f7a8/ 35DFBCB81E2845CC80256F56003CCEC5/\$file/ofrregs0504.pdf, accessed 10th July, 2006.

Department of Trade and Industry (DTI) (2004b) Corporate Social Responsibility - A Government Update, HMSO, available from: www.csr.gov.uk/pdf/dti_csr_final.pdf, accessed 10th July, 2006.

Godfrey, P.S. (1996) Control of Risk: A Guide to the Systematic Management of Risk from Construction, CIRIA, London, UK.

Jaunzens, D., Grigg, P., Cohen, R., Watson, M. and Picton, E. (2003) 'Building performance feedback: Getting started', in BRE Digest 478, BRE Press, London, UK.

Loy, H. and Coleman, P. (2006) 'Appraising building services systems for existing buildings in the 21st century', CIBSE National Conference: Engineering the Future, 21st-22nd March, London, UK, available from: http://www.cibse.org/pdfs/4a\%20-\%20Hsieh-min\%20Loy.pdf, accessed 10th July, 2006.

Nanayakkara, R. (2000) Condition Survey of Building Services, BSRIA, Bracknell, UK.

National Research Council (US) Committee on Business Strategies for Public Capital Investment (2004) Investments in Federal Facilities: Asset Management Strategies for the 21st Century, The National Academies Press, Washington, DC.

NHS (1993) Estatecode: Analysis of Estate Performance, The Stationery Office, London, UK.

Norman, G. and Flanagan, R. (1993) Risk Management and Construction, Blackwell Scientific Publications, Oxford, UK.

Robins, F. (2006) 'The challenge of TBL: A responsibility to whom?', Business and Society Review, 111(1), 1-14.

Royal Institution of Chartered Surveyors (RICS) (1997) Stock Condition Survey - A Guidance Note, RICS, London, UK.

Skillsware (2006) available from: www.skillsware.co.uk/twp/macr.htm, accessed 7th July, 2006.

Smith, N. (2003) Appraisal, Risk and Uncertainty, Thomas Telford Ltd, London, UK.

Thurm, D. (2005) 'Master of the house: Why a company should take control of its building projects', Harvard Business Review, 83(10), 120-129.

Wood, B. (2003) Building Care, Blackwell Science Ltd, Oxford, UK.

Woodhouse, J. (2001) Finding the Right Mix of Costs, Risks and Performance, The Institute of Asset Management, available from: www.iam-uk.org/downloads/ Costrisk\%20Works\%20Mgmt\%20article.pdf, accessed 10th July, 2006.

Woodhouse, J. (2003) Asset Management: Latest Thinking, The Woodhouse Partnership, available from: www.twpl.com/resources/Asset\%20Management\%20Latest\%20Thinking.pdf, accessed 10th July, 2006. 